\title{
The application analysis of MOOC+SPOC in advanced mathematics teaching under the background of big data
}

\author{
Xiaorong Zhu \\ Department of Information Science and Technology, \\ Taishan University, \\ Taian,China \\ smile_nine@126.com
}

\begin{abstract}
It's a new try to apply he MOOC+SPOC teaching model in the course of higher mathematics teaching under the background of big data. This paper mainly analyzes the problems existing in the teaching of advanced mathematics, and expounds the concept of MOOC+SPOC and the advantages and related problems of applying this model in higher mathematics teaching. It is a proper way to apply information technology to realize efficient teaching. It takes the innovation of learning style and teaching mode as the core, which has some certain theoretical and practical significances to promote the reform of higher mathematics teaching.
\end{abstract}

Keywords-Big data;MOOC+SPOC; Higher mathematics teaching

\section{INTRODUCTION}

Big data has become a hot topic of discussion in all walks of life. There are indications that our lives are increasingly inseparable from all kinds of data, and the world accesses to big data era rapidly.

Under the impetus of this change, the teaching of colleges and universities has also changed quietly. MOOC ,the large-scale network open curriculum, emerges in response to the proper time and conditions, which has received the widespread attention and the promotion application of the domestic and foreign educational fields.

In recent years, with the construction and development of the higher education informatization, the deep integration of information technology and educational technology promote the development of higher education, which put forward the challenge and request as for the teaching mode, learning mode and the school's management challenges and requirements ${ }^{[1]}$.

Higher mathematics, as an important basis of the traditional subject is inevitably affected by the influence of the age, and has to adapt to the trend of the development of education, improve the information literacy of teachers, and promote the teaching quality and efficiency. It is a new attempt to apply MOOC+SPOC teaching model in higher mathematics teaching, which has some certain theoretical and practical significances to promote the reform of higher mathematics teaching.

\section{THE DEVELOPMENT STATUS OF HighER MATHEMATICS TEACHING}

Higher mathematics is the basic course for college students majoring in mathematics. It is an important basis for students to study other subjects. Compared with middle school mathematics, higher mathematics is more extensive and deeper, but in essence they come down in one continuous line. At present, the higher mathematics teaching in our country presents the following development situation.

A. Higher mathematics teaching in many universities still adopts the traditional one-way knowledge teaching education mode.

This research was financially supported by the National Natural Science Foundation of China(Grant No.61402320). 
Teachers need only "a pen and a blackboard" to teach. In class, we can see everywhere that the teacher demonstrates the relevant formula on the blackboard while explaining the content of the teaching material.

In the traditional teaching mode, teachers pay too much attention to the process of theoretical deduction, ignoring the subject position of students in the process of learning, and run counter to the new curriculum education concept. At the same time, under the guidance of the teachers, the students passively accept all kinds of knowledge, so that students can not express their views on various issues, nor can they think deeply.

\section{B. The teaching material of higher mathematics is confused.}

The advanced mathematics textbooks used in some universities are written by themselves, and the contents of the textbooks are lack of scientific and systematic. Meanwhile, compared the development of the times, the textbooks written by themselves are often used for many years, and can not timely reflect the teaching content of higher mathematics new changes in the new era, which makes the teaching of mathematics and real life conflict.

\section{With the implementation of the concept of quality education, China's primary education has achieved certain results}

However, in the practice of higher mathematics education, we have found that the concept of quality education has been merge together with higher mathematics teaching process, but the implementation process of quality education still has a long way to go. Especially in the teaching evaluation, most of the universities still focus on the students' examination results, and the evaluation of other aspects of students' development is not in place.

It can be seen, at present, we still faces some difficulties during the process of teaching of Higher Mathematics in our country, including that the teaching idea is unscientific and the teaching methods are outdated, teachers play a main role in the teaching process, students' role are compressed, and the overall teaching effect is not very good.

\section{THE CONCEPT OF MOOC+SPOC.}

MOOC, that is, large-scale open courses, and SPOC refers to small-scale restricted online courses, compared with MOOC. SPOC sets the restricted access conditions on the students selecting course, only to meet certain requirements before they are allowed to SPOC classes. SPOC teaching mode mainly implements the flipped classroom for college students, and is a kind of teaching methods matching with the application of MOOC. The application of MOOC+SPOC mainly means that the students combine the autonomous learning using the open curriculum resources on the platform of MOOC with the limitation learning guiding by the teachers, and then the teachers answer the students' questions in formal class to communicate, discuss and cooperate with students.

\section{THE ADVANTAges OF MOOC+SPOC IN Higher MATHEMATICS TEACHING.}

\section{A. It fits the training goal of College students.}

The University advanced mathematics curriculum serves for the specialized course, whose goal is to raise the students' mathematics ability and the logical accomplishment, preparing for the students' follow-up study and the sustainable development. More and more attention has been paid to the application and practicality of mathematics curriculum. However, restricted by class hours and teaching conditions, mathematical modeling teaching and experimental teaching become a mere formality or can only be carried out among a small number of students, which weakens the practicability of mathematics and neglects the cultivation of students' ability and quality[3]. In the MOOC+SPOC teaching mode, the students accord to the needs of studying ,and autonomously learn the open curriculum resources on MOOC platform to master for the next course roughly, and then carry out the induced relearning according to the teachers' specific requirements and the produced problem in SPOC. In the process of classroom teaching, teachers mainly answer students' questions and focus on developing students' ability to solve practical problems with the studying knowledge. In this way, not only can enrich students' theoretical knowledge, but also can better 
improve students' practical operation ability.

B. It accords with student's study psychology.

Though college students have different mathematical bases and lack of confidence in learning mathematics, they are very familiar with the application of the internet. Using the MOOC+SPOC teaching model is easy to attract students' attention so that they can get into roles quickly. SPOC courses are typically 8 to 12 minutes long enough for students to use fragmentation time to learn, and do mobile learning. The content is refined, and a video course only explains a knowledge point or a problem, which is easy for students to learn and master. It is not easy to disperse the attention, which can fully mobilize the enthusiasm of students, and improve the teaching efficiency and the quality[4]. At the same time, the students are exposed to the world's latest technology and cutting-edge knowledge of mathematics and bring themselves a pleasant experience and curiosity, which is conducive to stimulate their enthusiasm and interest in learning mathematics.

C. It improves the elastic demand of college students to learn advanced mathematics.

The studying needs of college students are diverse, including the demand for employment for some students, and the need to continue to graduate school for the others. The higher mathematics curriculum should also consider the needs of the subsequent development of students. It is difficult for higher mathematics to meet the needs of students and not to increase the burden on students. MOOC+SPOC model can meet the needs of ubiquitous learning, and increase the elastic demand of college students to learn advanced mathematics. The learning video is presented in the form of micro courses. Students can freely control their learning time and place according to their own situation and learning characteristics, adjust the video rhythm, and internalize the knowledge more effectively. Students who are absent, do not have to worry about falling progress and not keeping up the rhythm of teaching[5]. It is not only convenient to learn by the theme, but also easy to use fragmentation time to learn. It also can use mobile platform to learn outside the classroom, and can better solve the problem of difference of learning content, progress and efficiency.

\section{It is helpfulfor teachers to innovate the classroom teaching mode.}

The traditional classroom teaching is generally undertaken by the teachers, and the teacher takes on the whole course design, curriculum development and teaching. The quality of classroom teaching depends on the individual teaching ability and teaching methods. In the MOOC+SPOC teaching model, teachers are the learners and integrators of curriculum resources. They do not have to be the main characters in the course teaching, and do not have to prepare for each course. They only need to integrate various online and physical resources according to the students' actual situation. Online, the teacher observes and follows the student's study progress, grasps the studying effect. In class, the role of the teacher is the instructor and facilitator, who organizes the students' group discussions, provides individualized guidance and helps students solve their problems. For some of the operational content, the teacher can hold seminars to demonstrate and operate, which greatly saves the teacher's time for preparing lessons and teaching time. The MOOC+SPOC teaching model can spare more time on the integration of resources or talking with the students, which is conducive to stimulate teaching enthusiasm and the classroom vitality, and innovate the classroom teaching mode.

\section{THE ADVICE FOR THE APPLICATION OF MOOC+SPOC IN HigHER MATHEMATICS TEACHING}

MOOC teaching is a simple online learning, more suitable for students with independent learning ability, and for self-control ability and higher mathematics learning ability of poor students, it has little effect. As a supplement to MOOC, SPOC can not replace the traditional classroom teaching, but it can be used to strengthen the guiding role of teachers. Adopting MOOC+SPOC mode can not only make up for the deficiency of MOOC, but also activate classroom teaching, improve students' participation and improve teaching quality. In the teaching of higher mathematics, MOOC+SPOC teaching reform is a systematic project, needing more efforts. The teachers should correctly handle the relationship between MOOC+SPOC and traditional classroom teaching, 
and rationally treat the opportunities and challenges brought out by MOOC+SPOC.

In conclusion, MOOC+SPOC combines the advantages of MOOC and traditional classroom teaching, and will be widely used in the field of education to realize the proper resource sharing, and to promote the education fair service. The application of MOOC+SPOC mode in the teaching of higher mathematics can make students form their own curriculum knowledge cognition through learning, thinking, integration of information. It is a practical way to achieve efficient teaching using information technology, reflect the value of online education. Taking the innovation of learning style and teaching mode as the core, it has certain theoretical and practical significance in promoting the reform of higher mathematics teaching and improving the quality of teaching in higher education institutions.

\section{REFERENCES}

[1] Luo Jiutong, Sun Meng, Gu Xiaoqing. Innovative research on MOOC from the perspective of Blended Learning: SPOC case study [J], Modern Educational Technology, 2014, 24 (7): 18-25.

[2] Kang Yeqin. Post MOOC era of Online education - SPOC analysis of [J]. Education Research of Tsinghua University, 2014,35 (1): 85-93.

[3] Xu Wei, Jia Yongzheng, Armando. Fawkes, and so on. From MOOC to SPOC - Academic dialogue based on MOOC practice of University of California at Berkeley and Tsinghua University. [J]. Modern Distance Education Research, 2014 (4): 13-22. 